\author{
Federal Reserve Bank of New York \\ Staff Reports
}

\title{
Asset Price Effects of Peer Benchmarking: Evidence from a Natural Experiment
}

\author{
Sushant Acharya \\ Alvaro Pedraza
}

Staff Report No. 727

May 2015

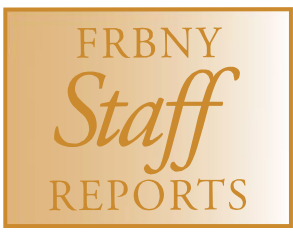

This paper presents preliminary findings and is being distributed to economists and other interested readers solely to stimulate discussion and elicit comments. The views expressed in this paper are those of the authors and do not necessarily reflect the position of the Federal Reserve Bank of New York or the Federal Reserve System. Any errors or omissions are the responsibility of the authors. 


\author{
Asset Price Effects of Peer Benchmarking: Evidence from a Natural Experiment \\ Sushant Acharya and Alvaro Pedraza \\ Federal Reserve Bank of New York Staff Reports, no. 727 \\ May 2015 \\ JEL classification: G12, G14, G23
}

\begin{abstract}
We estimate the effects of peer benchmarking by institutional investors on asset prices. To identify trades purely due to peer benchmarking as separate from those based on fundamentals or private information, we exploit a natural experiment involving a change in a government-imposed underperformance penalty applicable to Colombian pension funds. This change in regulation is orthogonal to stock fundamentals and only affects incentives to track peer portfolios, allowing us to identify the component of demand that is caused by peer benchmarking. We find that these peer effects generate excess stock return volatility, with stocks exhibiting short-term abnormal returns followed by returns reversal in the subsequent quarter. Additionally, peer benchmarking produces an excess in comovement across stock returns beyond the correlation implied by fundamentals.
\end{abstract}

Key words: herding, institutional investors, asset prices, comovement

Acharya: Federal Reserve Bank of New York (e-mail: sushant.acharya@ny.frb.org). Pedraza: The World Bank (e-mail: apedrazamorales@worldbank.org). The authors are grateful to the World Bank Research Committee for funding this research. This study has benefited from the comments of Pablo Cuba-Borda, Mark Jensen, Pete Kyle, John Shea, Paula Tkac, Shu Lin Wee, and Russ Wermers. The authors also thank seminar participants at the Inter-American Development Bank and the Federal Reserve Bank of Atlanta for comments and suggestions. They are grateful to Miguel Leaño for excellent research assistance. The views expressed in this paper are those of the authors and do not necessarily reflect the position of the Federal Reserve Bank of New York, the Federal Reserve System, or the International Bank for Reconstruction and Development/World Bank and its affiliated organizations, or those of the Executive Directors of the World Bank or the governments they represent. 


\section{Introduction}

In financial markets, institutional investors manage a significant portion of the total assets and account for an even greater portion of the trading volume. A commonly held view among practitioners and market observers is that institutional investors "herd", or trade excessively in the direction of the recent trades of other managers, which in turn has important implications for equilibrium prices. A rich theoretical literature has suggested several possible reasons for herding behavior. For example, managers may receive correlated private information, perhaps from analyzing the same indicator (investigative herding) or by eliciting information from the past trades of better-informed managers (informational cascades) and trade in the same direction (e.g Bikhchandani et al., 1992; Hirshleifer et al., 1994; Sias, 2004). Alternatively, managers might disregard private information and trade with the crowd due to the reputational risk of acting differently from their peers (reputational herding). ${ }^{1}$ Due to the fact that only trades are observed and not the incentives driving these trades, identification of the explanations for institutional herding is an outstanding empirical challenge.

Furthermore, these various reasons for correlated trading may affect asset prices in potentially conflicting ways. For example, if institutions herd due to informational motives, such herding may promote price discovery, faster adjustment of fundamental information into securities and more efficient markets (e.g., Froot et al. (1992) and Boehmer and Kelley (2009) find that institutional investors improve price efficiency). Conversely, if institutional investors systematically overlook their own private signals and trade with the crowd, prices may move away from fundamental values and display excess volatility. ${ }^{2}$ In this sense, relative performance concerns and incentives to track peer-group benchmarks among institutional investors may result in market failures and increase systemic risk (e.g. Dasgupta et al., 2011b; Guerrieri and Kondor, 2012; Acharya et al., 2013). Consequently, when studying correlated trading, it is essential to identify what are the

\footnotetext{
${ }^{1}$ Trueman (1994), Dasgupta et al. (2011b) and Vayanos and Woolley (2013) among many others.

${ }^{2}$ For evidence on short-term return continuation following institutional herding, see, for example, Wermers (1999) and Sias (2004). Dasgupta et al. (2011a) find evidence of long-term return reversals after institutional herding. Further evidence on institutional herding and long-term reversals can be found in Gutierrez and Kelley (2009) and in Brown et al. (2014).
} 
underlying reasons that drive such behavior in the first place. In this paper we concentrate on the asset price effects of demands arising from herding due to the investors' desire to track peer-group benchmarks. We refer to this as the demand due to peer benchmarking.

To isolate the component of demand which arises solely due to peer benchmarking (and is orthogonal to investigative herding and informational cascades), we study trading behavior by Colombian pension fund managers in the presence of a peer-based under-performance penalty known as the Minimum Return Guarantee (MRG). An under-performance penalty like the MRG resembles a reputational risk, in that the manager is penalized for having significantly lower returns than her peers. ${ }^{3}$ With the MRG, the risk is explicit as the manager will be penalized financially if returns are below the maximum allowed shortfall relative to the peer benchmark. In June 2007, the Colombian government changed the MRG formula, increasing the maximum allowed shortfall and thereby loosening the MRG. This policy change affects the propensity of pension fund managers to track the portfolio of their peers and is exogenous to stock fundamentals. This natural experiment enables us to identify herding arising solely due to to peer benchmarking considerations.

Exploiting the change in the MRG, first, we estimate demands for a particular stock by pension funds due to peer benchmarking. In particular, we test for differences in trading behavior by the pension fund managers (PFAs) before and after the policy change. We show that prior to June 2007, with a tighter MRG, PFAs were more likely to trade in the direction of peers, a behavior that was more pronounced for under-performing managers. Managers minimize the risk of falling below the minimum return requirement by shifting their portfolio closer to their peers, with larger shifts when the MRG was more strict. Second, we use the estimated demands to test whether pension fund trades driven by peer benchmarking affect stocks' contemporaneous returns, subsequent returns, and the level of comovement with other securities in the peer portfolio.

While there is a large empirical literature which studies herding by institutional investors, most of these studies measure herding indirectly and in particular must infer indirectly the reason why herding might be taking place. In a large portion of the literature, herding has usually been measured as trade clustering. For example, an early study by Lakonishok et al. (1992) measures

\footnotetext{
${ }^{3}$ The MRG is also common in many countries that moved from defined benefit pension systems to defined contributions systems based on individual accounts. See for instance Turner and Rajnes (2001) for a review on these systems and Kritzer et al. (2011) for other Latin American countries with MRG requirements.
} 
herding as the contemporaneous correlation of trades in a particular security. Studies using similar measures such as Grinblatt et al. (1995), Wermers (1999), Wylie (2005) and others find statistically significant, but relatively weak, evidence of institutional investors herding in the average stock. More recently, Sias (2004) and Choi and Sias (2009) compare correlated trading among different institutional investors and indirectly infer whether it is reputational or informational herding. Their identification of these reputational motives relies on the premise that if such concerns were to drive herding, institutions with higher redemption risks and greater short-term market monitoring, such as mutual funds and independent advisors, should exhibit a greater propensity to herd than other investors. However, since this clustering may be because of various reasons other than herding, it is hard to distinguish actual herding from spurious herding. The key distinction (and advantage) that our empirical strategy has over most of the existing literature is that we are able to directly identify demand due to peer-benchmarking considerations without relying on indirect inference to identify motives for correlated trading. Consequently, we can estimate the implications for asset prices directly.

Our results indicate that institutional investors' demands due to peer benchmarking considerations have both statistically and economically significant effects on asset prices. Trades motivated by peer benchmarking generate 3.53 percent of contemporaneous abnormal returns on the average stock. These excess returns are fully reversed after six months, indicating that peer-effects among pension funds tend to generate excess volatility in stock prices. We also find that when the funds are buying a stock to track the peer portfolio, the stock price starts moving more with the prices of other stocks in the peer portfolio. This increase in comovement is persistent over the next six months following the trades of the PFAs and is not explained by economic fundamentals. Overall, our findings suggest that peer effects and relative performance concerns among institutional traders reduce market efficiency.

These findings provide credence to a fast growing theoretical literature which studies how asset prices are affected by compensation structure of money managers and other complementarities in asset management. For example, Malliaris and Yan (2011), Dasgupta et al. (2011b), Guerrieri and Kondor (2012) and Vayanos and Woolley (2013) argue that short-term market monitoring (which 
typically relies on past returns to gauge managerial ability) could induce low-ability managers to mimic high-ability managers. They argue that such herding behavior could potentially explain short-term momentum and long-term reversal in asset returns, and in some situations might amplify shocks to asset prices. Similarly, Dasgupta and Prat (2008) and He and Krishnamurthy (2013) study equilibrium effects of delegated portfolio management when poor relative performance of fund managers triggers portfolio outflows due to contracting frictions. They too find that the reputational concerns of fund managers may imply an endogenous tendency to imitate past trades, which impacts the prices of the assets both in the short and long run. In the context of our paper, the MRG is an explicit penalty on under-performance and induces similar behavior in managers as the papers mentioned above. To our knowledge, our results provide the first direct evidence on the impact of relative-performance-concerns driven trades on stock returns.

Our findings are also related to a broader literature that studies the asset price effects of institutional trading. This literature broadly tries to understand whether institutional traders move asset prices because they have market power or if the price effects relate to an informational advantage these large traders might have. In order to separate out the role of new information, many studies have focused on events when stocks are added to or deleted from an index. ${ }^{4}$ Overall, this literature has found evidence that institutional trading does in fact have price effects. For example, Barberis et al. (2005) show that stocks added to the S\&P 500 index experience increased comovement of returns with the rest of the index and Boyer (2011) shows that economically meaningless index labels cause stock returns to covary in excess of fundamentals, while Kaul et al. (2000) find excess returns in stocks after an uninformative rebalance of the constituents of the Toronto stock exchange 300 index. ${ }^{5}$ We contribute to this literature by estimating the asset prices effects from institutional trades due to peer-benchmarking incentives among pension fund managers. In our set up, pension funds benchmark against the peer portfolio to guard against underperformance. This is similar to the behavior of index funds and exchange-traded funds written on an index who cling to their benchmark index to avoid under-performance. We find that

\footnotetext{
${ }^{4}$ Harris and Gurel (1986), Shleifer (2000) and Chen et al. (2004) present evidence from index additions and deletions, while Greenwood (2005) and Hau (2011) present evidence from more general index redefinitions.

${ }^{5}$ However, the uninformativeness of stock addition and deletions has been questioned. For example, see work such as Denis et al. (2003) and Cai (2007).
} 
peer benchmarking generates contemporaneous excess returns and excess in comovement across stock returns, similar to the evidence on stock additions to widely follow indexes.

The rest of the paper is organized as follows. In section 2 we describe the data and provide some institutional features of the MRG and the Colombian financial markets. In section 4 we perform our empirical exercises. We conclude in Section 5.

\section{Institutional Setting}

To facilitate an understanding of the data and the Colombian institutional environment, we begin with a brief description of the Colombian private pension industry and the portfolio and stock data.

\subsection{Pension Fund Administrators (PFAs)}

Between January 2004 and December 2010, there were six private PFAs. By June 2010, these Colombian Pension Funds had $32 \%$ of their $\$ 44$ billion invested in domestic stocks, which amounted to $7.1 \%$ of the total domestic market capitalization. In addition to this, during 2010, conditional on trading, the average monthly change in the holding of a stock was $13 \%$ of the average trading volume on the same stock. ${ }^{6}$ Hence, not only do these funds make up for a significant portion of the domestic stock market, but they also represent a large fraction of the trading volume, and stock price effects due to their trading behavior is likely to be present.

The PFAs are in charge of the mandatory contributions of the working population. The worker investment decision is restricted to the choice of the PFA, while the PFA is in charge of the portfolio allocation. Each PFA pools the contributions of the workers into one fund. Consequently, any worker associated with a PFA has an exact same asset allocation independently of the age or size of its contributions as any other worker with the same PFA. ${ }^{7}$ The government regulates PFAs' portfolio strategies by imposing limits on specific asset classes and individual securities for these

\footnotetext{
${ }^{6}$ Here trading refers to the change in holdings for a given stock during a month. Total volume trading for each stock is calculated as the average volume trading during the year.

${ }^{7}$ Starting in 2011, PFAs were allowed to offer three different funds with different risk profiles.
} 
funds ${ }^{8}$, and through the definition of the Minimum Return Guarantee.

The MRG imposes a lower threshold of returns that each individual PFA needs to guarantee for its investors. If a PFA fails to provide at least this return, the PFA must transfer part of its own net worth to the fund to make up the shortfall. The MRG is assessed by comparing the fund's average annual return over the previous three years to the average of the six PFAs. ${ }^{9}$ Between January 2004 and June 2007, the minimum return guarantee allowed for a shortfall of 30 percent from the average annual return over the previous three years for all PFA's. In other words, if $\Pi_{t}$ denotes the average across PFA's of the average annual return over three years, then the MRG required a minimum return of $70 \% \Pi_{t}$ for each PFA. After June 2007, the government changed the formula for the lower threshold on the return for each PFA to $\min \left\{70 \% \Pi_{t}, \Pi_{t}-2.6 \%\right\}$. Note that this new formula implies that for industry returns below 8.66\%, the new formula implies a minimum return of $\Pi_{t}-2.6 \%{ }^{10}$ Between December 31, 2006 and December 31, 2009 the industry annual average returns were $6.01 \%$. With the new formula in place, the minimum return would be calculated as $3.41 \%$, instead of the $4.20 \%$ that would have been calculated under the older formula. This effectively implied a loosening of the MRG requirement after June 2007.

\section{$2.2 \quad$ The data}

The data in this paper were collected from three sources. Information on portfolio holdings by Colombian Pension Funds was provided by the Colombian Association of Pension Fund Administrators (ASOFONDOS). It includes the detailed security allocations for the funds managed by each of the six PFAs on a monthly basis for the period 2004:1 to 2010:12. We use Compustat Global for stock-specific information, i.e. price, trading volume, and firm size. However, Compustat Global has missing observations for several of the domestic stocks held in the pension fund portfolios. We collect missing information directly from the Superfinanciera de Colombia (SFC), a supervisory agency within Colombia's Finance and Public Credit Ministry which oversees all

\footnotetext{
${ }^{8}$ In June 2008 some of the limits were: (i) Maximum $50 \%$ on domestic government debt. (ii) Maximum $40 \%$ on equity securities. (iii) Maximum $40 \%$ on foreign securities.

${ }^{9}$ See Kritzer et al. (2011) for other Latin American countries with MRG requirements.

${ }^{10}$ Notice that $70 \% \Pi=\Pi-2.6 \%$ for $\Pi=8.66$ percent. For $\Pi<8.66$ percent, $70 \% \Pi>\Pi-2.6 \%$ and hence the minimum return required is $\Pi-2.6 \%$.
} 
financial, insurance and pension services in the country. Pension funds' holdings are presented in Table 1 at two-year intervals. ${ }^{11}$

[Insert Table 1 about here]

Table 2 presents monthly averages of stock-level information before and after the MRG change. Additionally, the SFC reports a quarterly Liquidity Score on each stock which ranges from 0 to 10, based on the number of trades and average trading volume. With this measure each stock is classified into one of four categories of marketability. We also split our sample into stocks with $H I G H$ marketability as reported by the SFC, and $L O W$ marketability for all other stocks.

[Insert Table 2 about here]

\section{Portfolio decisions of PFAs under the MRG}

Our objective is to test whether trades by pension funds affect stocks' contemporaneous returns, subsequent returns, and the level of comovement across domestic stock prices. In particular, we focus on trades motivated by peer benchmarking. Under the MRG, the returns of a PFA are evaluated relative to the average returns of all the PFA's. A PFA which is performing poorly relative to its peers has an incentive to mimic the portfolio of the others so as to come closer to the average return. Thus, due to the structure of the MRG, pension funds are benchmark against their peer-group portfolio to avoid the penalty associated with failing to deliver the minimum allowable return.

The penalty for falling too far behind the industry average returns may lead the PFA to bankruptcy. Given the size of each PFA, and the total value of assets under management, a typical Colombian PFA falling 50bps below the MRG threshold would use up its entire net worth compensating its investors. ${ }^{12}$ With such a severe penalty, one should expect that the MRG is of

\footnotetext{
${ }^{11}$ Throughout the sample period, net flows to these funds were positive, which reflects the fact that most of the workers contributing to these funds are still young (more than $70 \%$ were younger than 40 years old as of December, 2010).

${ }^{12}$ In the 15 year history of the private pension system (between 1996 and 2010), no PFA ever yielded returns below the MRG. Even in the global turmoil of October 2008, the PFA with the lowest returns managed to have returns 118bps above the minimum threshold specified by the MRG (this is the closest any PFA was to falling short of the MRG stipulated threshold in the sample period).
} 
first order importance when PFAs set their strategies.

Furthermore, the propensity to herd, or track the peer portfolio is increasing in the strictness of the MRG. The smaller the allowed short-fall from the industry average return, the greater is the incentive for each PFA to benchmark against their peer-group portfolio so as to avoid the penalty.

To summarize overall trading strategies by PFA's in response to the MRG change, we calculate the correlation between the monthly trades of PFAs on each stock and the peer portfolio. Our objective here is to provide a general description of trading behavior and strategies of Colombian pension fund managers in a parsimonious way. Let $w_{i, s, t}$ denote the weight of stock $s$ on the portfolio of pension fund $i$ at the end of month $t$. The industry or peer portfolio refers to the holdings of all six pension funds in each stock $\left(\pi_{s, t}\right)$. We define overexposure as the weight of stock $s$ on fund $i$ relative to the weight in the peer portfolio, i.e. oexp $p_{i, s, t}=w_{i, s, t}-\pi_{s, t}$. For each stock, demands by pension funds during each month are denoted by $y_{i, s, t}$.

\section{[Insert Figure 1 about here]}

Figure 1 depicts the time series behavior of the correlation between pension fund demands and lagged overexposure, $\operatorname{corr}\left(y_{i, s, t}, \operatorname{oexp}_{i, s, t-1}\right)$. For each month, the correlation is calculated across all stocks and for all pension funds over a six months rolling window. According to the figure, PFAs were more likely to buy stocks with underexposure $($ oexp $<0)$ prior to the MRG formula change in June 2007 than after this date. The average correlation between trades and overexposure before June 2007 was $-14.0 \%$ which is significantly different from zero at the $99 \%$ confidence level. For months after June 2007 in the sample, the average correlation was $2.5 \%$. In other words, with a tighter MRG, PFAs are more likely to trade in the direction of the peer portfolio, buying stocks with lower participation relative to their peers.

In addition to the above relationship, we are also interested in the behavior across funds given their performance relative to the peer group. For example, at any point in time, under-performing funds have a higher exposure to the penalty, and potentially their trading towards the peer group might be more pronounced. Relative performance with respect to the peer portfolio is defined as rel $_{i, t}=R_{i, t}-R_{-i, t}$, where $R_{t}$ are 36 month returns prior to $t$ (consistent with the measurement period of the MRG). The relative performance variable $\mathrm{rel}_{i, t}$ measures whether fund $i$ is over- 
performing $\left(\right.$ rel $\left._{i, t}>0\right)$ or under-performing $\left(\right.$ rel $\left._{i, t}<0\right)$ at time $t$ relative to the other PFAs. Figure 1 also presents the time series behavior of the correlation between trades and one month lagged interaction between overexposure and relative performance, $\operatorname{corr}\left(y_{i, s, t}, \operatorname{oexp}_{i, s, t-1} \times \operatorname{rel}_{i, t-1}\right)$. The positive correlation between trades and the interaction term before June 2007 implies that, with a tighter MRG, an under-performing manager is more likely to buy stocks in which she is underexposed relative to the peer portfolio than to buy stocks with overexposure. That is, PFAs with poor relative performance seem to be moving more strongly towards the peer group when the MRG is more strict.

To summarize, the evidence suggests that a more strict MRG prior to June 2007 is associated with more trading in the direction of peers, a behavior that was more pronounced for underperforming managers. For a detailed study of the behavior of pension funds under the MRG, see Pedraza (2015). ${ }^{13}$

\section{Estimation Framework and Results}

The primary object of interest in this paper is to test whether trades by pension funds (and in particular, those motivated purely by peer benchmarking) affect stocks' contemporaneous returns, subsequent returns, and the level of comovement across domestic stock prices. As mentioned earlier, identifying these effects is not trivial because of the following reasons: (i) since one cannot observe what motivates a trade in the first place, it is hard to distinguish if the movement in asset prices following a trade just reflects changing fundamentals or not, and (ii) it is even harder to identify asset price effects due to demands arising solely due to peer benchmarking because, in general, one cannot disentangle the component of demand that can be solely explained by the desire to peer benchmark.

The change in the MRG in June 2007 provides us with a natural experiment which we exploit in order to identify a component of demand which is unrelated to a change in fundamentals and is purely driven by the desire to peer-benchmark. Our identification strategy relies on two key related elements: (1) given the MRG, pension funds are incentivized to benchmark against their

\footnotetext{
${ }^{13}$ Pedraza (2015) studies the trading behavior but abstracts from the asset price effects from such trading behavior.
} 
peer-group portfolio, and (2) the loosening of the MRG requirement in June 2007 affects the incentive for peer benchmarking by individual PFAs but is unrelated to stock fundamentals.

\subsection{The Effect on Stock Returns}

Our main interest is in estimating the asset price effect of the trades by the PFA's. We start by testing whether pension funds' demands on a given stock are related to the stock returns. The following equation summarizes the relationship to be estimated:

$$
a r_{s, t}=\beta_{0}+\beta_{s}+\beta_{t}+\beta_{1} y_{s, t}+\beta_{2} l i q_{s, t}+\beta_{3} y_{s, t} \times l i q_{s, t}+\Upsilon x_{s, t}+\varepsilon_{s, t}
$$

where $a r_{s, t}$ denotes the abnormal returns associated with stock $s$ during month $t$, calculated as $a r_{s, t}=r_{s t}-E\left[r_{s, t}\right]$, where $r_{s, t}$ are stock returns between $t$ and $t+1$ and expected returns are calculated relative to the IGBC index, a widely used value- and liquidity-based index for the Colombian stock market. Total demand for each stock by all pension funds during a month is calculated as $y_{s, t}=\sum_{i=1}^{6} y_{i, s, t}$. Stocks' liquidity is captured by $l i q_{s, t}$. To investigate the price effects from institutional trades on stocks with different liquidity we include the interaction with pension funds demands $\left(y_{s, t} \times l i q_{s, t}\right) .{ }^{14}$ In addition to these right-hand side variables, we also include some stock specific controls $x_{s, t}=\left\{a r_{s, t-1}\right.$, asset $\left._{s, t}\right\}$. We include past abnormal returns to control for momentum trading. ${ }^{15}$ This popular investment strategy has been widely documented to be relevant in explaining demands by institutional investors. ${ }^{16}$ We also control for firm size during the observation month $\left(\right.$ assets $\left._{s, t}\right)$, defined as the logarithm of firms' total book value of assets, since institutional investors may share an aversion to securities with certain characteristics. For example, Wermers (1999) finds evidence that US mutual funds tend to herd in small stocks.

To test whether current pension fund demands are correlated with subsequent stock returns

\footnotetext{
${ }^{14}$ For example, Brown et al. (2014) find that, return reversals following mutual funds trades are mostly concentrated for small and illiquid stocks.

${ }^{15}$ Momentum trading is defined as purchasing (selling) assets with positive (negative) past returns. Selling past losers can also be explained by window dressing. For US pension funds see Lakonishok et al. (1991). Chan et al. (1996) suggests that momentum trading may be caused by a delayed reaction of investors to the information in past returns and past earnings.

${ }^{16}$ See Grinblatt et al. (1995), Grinblatt and Keloharju (2000) among many others. Raddatz and Schmukler (2012) also document the presence of momentum trading for Chilean PFAs.
} 
we estimate equation (1) using future abnormal returns as the dependent variable. More precisely, we use abnormal returns in the contemporaneous quarter $a r_{s, q}$, and the following two quarters, $a r_{s, q+1}$ and $a r_{s, q+2}$. We account for time-invariant heterogeneity across stocks by including stock fixed effects $\left(\beta_{s}\right)$ and time-specific effects by including year fixed effects $\left(\beta_{t}\right)$. The coefficient $\beta_{1}$ measures how pension funds demands are related to abnormal returns over time and across stocks. Given the potential persistence, we allow the error term $\left(\varepsilon_{s, t}\right)$ to be correlated within stocks and correct the standard errors as in Petersen (2009). Finally, we standardize fund demands and the liquidity score so that the estimated coefficients are directly informative about their economic significance.

[Insert Table 3 about here]

The first four columns of Table 3 present the estimation results of equation (1) via OLS, for both measures of liquidity (i.e. marketability dummy and the liquidity score). Demands by pension funds are positively correlated with contemporaneous abnormal returns and negatively correlated with abnormal returns in subsequent quarters. These relations are stronger for stocks with lower liquidity.

In other studies (e.g. Brown et al., 2014), evidence on overreaction in stock prices and stock return reversals following institutional trades is often interpreted as indirect evidence of herding that is not related to information. However, equation (1) is most likely misspecified since we cannot observe why a trade originates. In particular, if trades are based on private information about stock returns, the assumption that $\left(y_{s, t}, y_{s, t} \times l i q_{s, t}\right) \perp \varepsilon_{s, t}$ is violated which implies that the estimated coefficients may be biased and inconsistent. To circumvent this issue, we use an instrumental variable (IV) approach. As discussed earlier, the change in the MRG provides a suitable instrument. In particular, the change in the MRG affects peer benchmarking and is an exogenous event orthogonal to any changes in excess returns of individual stocks. We use the dummy variable $\mathrm{MRG} \in\{0,1\}$ as one of the instruments. It represents the policy change and is equal to one for dates before June 2007 and zero thereafter. In addition we include other instruments in the form of interactions with the MRG dummy. More precisely, we estimate pension 
funds' demand and its interaction with liquidity as follows

$$
\begin{gathered}
y_{s, t}=\alpha_{0}+\alpha_{s}+\alpha_{t}+\sum_{i=1}^{6} \gamma_{i} W_{i, s, t-1}+\delta_{0} \mathrm{MRG}_{t}+\sum_{i=1}^{6} \delta_{i} W_{i, s, t-1} \times \mathrm{MRG}_{t}+e_{s, t}^{1} \\
y_{s, t} \times l i q_{s, t}=\bar{\alpha}_{0}+\alpha_{s}+\bar{\alpha}_{t}+\sum_{i=1}^{6} \bar{\gamma}_{i} W_{i, s, t}+\bar{\delta}_{0} \mathrm{MRG}_{t}+\sum_{i=1}^{6} \bar{\delta}_{i} W_{i, s, t} \times \mathrm{MRG}_{t}+e_{s, t}^{2}
\end{gathered}
$$

where $W_{i, s, t}$ are fund-stock specific controls related to peer benchmarking, i.e. overexposure, relative performance vis-à-vis the peer group and the interaction between these two variables, $W_{i, s, t}=\left\{\operatorname{oexp}_{i, s, t}, \operatorname{rel}_{i, t}, \operatorname{oexp}_{i, s, t} \times \operatorname{rel}_{i, t}\right\}$. Equations (2) and (3) are the first-stage of the IV estimation. These equations are expected to capture the behavior documented in Section 3. That is, with a tighter MRG, PFAs are more likely to buy stocks with underexposure $(M R G \times \operatorname{oexp}<0)$, an effect that is stronger under-performing funds $(M R G \times$ oexp $\times r e l>0)$. Other literature supports the use of these controls. For example, in the context of U.S. equity mutual funds, Basak et al. (2007) find different behavior among funds depending on whether managers are ahead or behind the S\&P 500 index.

We now turn to the estimation on abnormal returns. Denote the fitted values of $y_{s, t}$ from equation (2) by $\widehat{y}_{s, t}$. Note that $\widehat{y}_{s, t}$ represents the component of aggregate demand for stock $s$ in month $t$ which arises because of peer-benchmarking considerations. Using $\widehat{y}_{s, t}$ as our measure of demand in equation (1) is no longer fraught with the issues pointed out before as this is the component of demand which does not originate because of private stock-specific information (provided that we control for the direct effect of $W_{i, s, t}$ on abnormal returns in equation 1 ).

Columns (5) through (8) of Table 3 present the results of estimating equation (1) using the instrumented aggregate demand for each stock. ${ }^{17}$ Trades by these pension funds seem to have strong effects on contemporaneous returns. Trades motivated by peer benchmarking generate $3.53 \%$ of contemporaneous abnormal returns on the average stock. These abnormal returns are fully reversed after two quarters. Figures 2 display the marginal effects of demands on abnormal returns for stocks with different levels of liquidity. The figures also compare results from the OLS specification with the IV regressions. The figures indicate that both, the excess returns in the

\footnotetext{
${ }^{17}$ The Table also includes p-values of the "Differences-in-Sargan" test for endogeneity and the Hansen overidentification test.
} 
contemporaneous month and the reversal after two quarters are stronger for stocks with lower liquidity.

[Insert Figure 2 about here]

Our results indicate that there is an overreaction in stock prices followed by a reversal. In related theoretical work, Dasgupta et al. (2011b) show that such behavior is consistent with the presence of investors with relative performance concerns. Dasgupta et al. (2011b) argue that a manager may be willing to overpay to buy an asset because of relative performance concerns and other market participants extract the surplus by overcharging. They also show that the degree of reversal in returns is higher with stronger relative performance concerns. Our estimation results provide support for these theoretical findings. We find that when the magnitude of trades motivated by peer benchmarking is larger there are higher abnormal returns during the contemporaneous month, and larger reversals in the subsequent quarter. In our setting, a manager may be willing to overpay for a stock when she needs to reduce the likelihood of under-performance, or at least to guarantee that her performance is not below the MRG. The results indicate that institutional investors' peer-benchmarking generates excess volatility in stock prices and these effects are stronger when the incentive to be closer to the peer-group is more pronounced. To our knowledge, our results are the first direct evidence on the impact of relative performance concerns driven trades on the prices of stocks.

\subsection{Comovement}

In addition to the effect of peer benchmarking on abnormal returns, we also study how peer benchmarking may result in excess comovement among stocks in the peer portfolio. The traditional explanation for why a group of stocks move in tandem is that they have correlated earnings news and the covariation in returns merely reflects covariation in fundamentals. Alternatively, Barberis and Shleifer (2003) suggest that stock prices can covary in excess of fundamentals if investors allocate funds across security labels rather than on individual securities, a practice known as "style

investing". The capital flows of such an investor in and out of specific assets are perfectly correlated 
across securities with the same label even though the fundamental values of these securities are at most only partially related. There is compelling evidence supporting the excess in covariance generated by index recompositions (Barberis et al., 2005; Boyer, 2011). In our context, if pension fund managers follow their peer group closely to protect against underperfomance, flows by these managers might generate excess comovement in the price of stocks belonging to the peer portfolio.

In this section we test whether peer benchmarking incentives among Colombian pension funds affect the level of comovement across domestic stocks. We start by estimating equation (1) using the correlations between daily stock returns and the returns of the peer portfolio as the dependent variable $\left(\operatorname{corr}_{s, t}^{n}\right) .{ }^{18}$ This correlation is measured over one month $\left(\operatorname{corr}_{s, t}^{1}\right)$, two months $\left(\operatorname{corr}_{s, t}^{2}\right)$, three months $\left(\operatorname{corr}_{s, t}^{3}\right)$ and six months $\left(\operatorname{corr}_{s, t}^{6}\right)$ rolling windows, following the trades of pension funds. We include the lagged dependent variable and firm size as controls in $x_{s, t}$ as well as firm and year fixed effects.

Results from this OLS specification are presented in Table 4, columns (1) through (4). The shortcomings of the previous specification are twofold. First, the covariance of stock returns might be affected in opposite ways given the source of trading. For instance, trading on private firmspecific information is expected to increase the fraction of total volatility due to idiosyncratic shocks and make stock returns less correlated in the cross-section. Conversely, trading to track the peer group might increase the covariance across stock returns given the correlated flows into or out of the stocks in the peer portfolio. Since these motives for trading compound at different times, the OLS estimation above could underestimate the effects of peer benchmarking on comovement. Second, pension funds flows might increase exactly when the covariance structure of fundamental values also changes. In this case, an increase in stock comovement following pension funds trades would reflect changes in fundamentals rather than the effects from institutional investors flows into these assets.

We use our IV approach to estimate the actual effects on comovement from peer-benchmarking and to test the validity of the hypothesis that all comovement can be explained by correlated fundamentals. We use estimated demands $\widehat{y}_{s, t}$ from equation (2). Following the discussion in the

\footnotetext{
${ }^{18}$ To avoid spurious correlation between the stock returns and the peer portfolio, we exclude stock $s$ from the peer portfolio to calculate daily returns.
} 
previous section, $\widehat{y}_{s, t}$ is the component of demand which does not originate because of firm-specific information and, moreover, is unrelated to the covariance structure of firms' earnings.

[Insert Table 4 about here]

Columns (5) through (8) of Table 4 present results from the IV specification. Our evidence indicates that pension fund trades which are motivated by peer benchmarking generate excess in comovement across stocks returns during the months following the trades. To verify the statistical significance of pension fund trades on excess comovement, we calculate the marginal effects of demands. These marginal effects are depicted in Figure 3. Each panel in Figure 3 compares results from OLS and IV specifications for different levels of stock liquidity. While the OLS results suggest that there is no evident change in comovement across stocks following the trades by pension funds, the IV specification implies the opposite. As discussed earlier, the predictions of the OLS model may be explained by the fact that some of the trades by these institutional investors might result from stock-specific information, which is expected to reduce the correlation between the stock returns and the returns of other stocks in the peer portfolio. The IV results show that peer benchmarking generates excess in comovement between stocks returns and the peer portfolio, an effect that last for at least six months. For the average stock, peer benchmarking increases the correlation of daily stock returns by 0.37 during six months. This is a sizable increase in comovement, since average stock return correlation over the sample period is 0.46 . According to Figure 3, stocks with lower liquidity display larger increases in comovement with the peer portfolio.

[Insert Figure 3 about here]

We also use an alternative measure of stock return variation that is firm-specific, commonly known as price non-synchronicity. This measure is defined as $\ln \left(\left(1-R_{s, t+n}^{2}\right) / R_{s, t+n}^{2}\right)$, where $R_{s, t+n}^{2}$ is the $R^{2}$ from the regression of firm i's daily returns and the peer portfolio returns during n-month rolling windows following $t$. This measure is typically used to capture firm-specific information in stock prices (Roll, 1988). ${ }^{19}$ Following the empirical strategy above, we test whether peer bench-

\footnotetext{
${ }^{19}$ To calculate $R^{2}$, stock returns are typically regressed on the returns of a market index. In our case, the correlation between the peer portfolio and the Colombian market index (IGBC) is $82 \%$. In unreported results we calculate price non-synchronicity using the IGBC for which results are quantitatively similar to the ones presented here. In both cases, the peer portfolio and market portfolio exclude the firm in question. This exclusion prevents spurious correlations between firm and both index and peer portfolio returns.
} 
marking impacts price non-synchronicity over one, two, three and six months following the trades of pension funds. Results are documented in Table 5. Consistent with the observed excess in comovement above, stocks with large flows from pension funds due to peer benchmarking tend to exhibit lower idiosyncratic volatility, or a higher fraction of total volatility that is common to all stock in the peer group.

[Insert Table 5 about here]

\section{Conclusions}

Effective management of retirement savings is fast becoming an important agenda in many countries due to a rapidly ageing population. In addition to fulfilling this critical function, pension funds, which are theoretically long-only investors, perform an important role by providing longterm financing and liquidity to the rest of the financial system. These large institutional investors are often thought of as stabilizers for the financial system and are expected to behave in a patient, counter-cyclical manner, making the most of cyclically low valuations to seek attractive investment opportunities. Moreover, since pension funds are usually thought of as investing for the long-term, these institutions have generally not been thought of as adding to systemic risk but this belief is fast changing (Shin, 2013).

This paper highlights how financial regulation may alter the behavior of pension funds and other long-term institutional investors. The MRG is intended to protect the interests of the working population by limiting unnecessary risk taking by pension fund managers. However, by relying on a benchmark based on peer returns, the regulation effectively incentivizes herding. Consequently, asset prices in the domestic market move in the short and medium run due to forces independent of fundamentals. Furthermore, these short-term considerations make these long-horizon traders also behave pro-cyclically, adding to systemic risk rather than stabilizing the system as was previously thought. Whether the welfare loss from this increased financial market

inefficiency is clouded by the reduction in other forms of risk taking is still an open question and requires further investigation. 
The evidence in this paper can be seen as providing credence to a large theoretical literature which emphasizes the role of reputational and relative performance concerns among institutional money managers on asset prices. The main contribution over a bulk of the existing literature can be seen in the fact that we are able to identify demands due to peer-group effects. The empirical literature typically measures herding indirectly as decision clustering. However, decision clustering may be driven by multiple forces acting simultaneously and it is hard to differentiate the role of relative performance concerns in correlated trading. Further, by being able to differentiate herding that exclusively results due to peer benchmarking considerations from that due to informational advantages, we are able to clearly identify the asset price effects associated with such herding.

While the evidence presented in this paper is from Colombian pension funds, and results are linked to the Colombian domestic market structure and size, the results of this paper should be interpreted more generally. The paper provides evidence and estimates of how complementarities in asset management are likely to affect equilibrium outcomes in financial markets. The complementarities in this paper arose from the imposition of an explicit benchmark by regulation but they are as likely to arise from reputational considerations based on relative performance.

\section{References}

Acharya, Viral, Marco Pagano, and Paolo Volpin, "Seeking Alpha: Excess Risk Taking and Competition for Managerial Talent," NBER Working Paper No. 18891, 2013.

Barberis, Nicholas and Andrei Shleifer, "Style Investing," Journal of Financial Economics, 2003, 68 (2), 161-169.

_ , _, and Jeffrey Wurgler, "Comovement," Journal of Financial Economics, 2005, 75 (3), $284-317$.

Basak, Suleyman, Anna Pavola, and Alexander Shapiro, "Optimal Asset Allocation and Risk Shifting in Money Management," Review of Financial Studies, 2007, 20 (5), 1583-1621.

Bikhchandani, Sushil, David Hirshleifer, and Ivo Welch, "A Theory of Fads, Fashion, Custom, and Cultural Change as Informational Cascades," Journal of Political Economy, 1992, $100(5), 992-1026$.

Boehmer, Ekkehart and Eric Kelley, "Institutional Investors and the Informational Efficiency of Prices," Review of Financial Studies, 2009, 22 (9), 3563-3594.

Boyer, Brian, "Style-related ComovementL Fundamentals or Labels?," Journal of Finance, 2011, 66 (1), 307-332. 
Brown, Nerissa, Kelsey Wei, and Russ Wermers, "Analyst Recommendations, Mutual Fund Herding, and Overrection in Stock Prices," Management Science, 2014, 60 (1), 1-20.

Cai, Jie, "What's in the News? Information Content of S\&P 500 Additions," Financial Management, 2007, 36 (3), 113-124.

Chan, Louis K. C., Narasimhan Jegadeesh, and Josef Lakonishok, "Momentum Strategies," Journal of Finance, 1996, 51 (5), 1681-1713.

Chen, Honghui, Gregory Noronha, and Vijay Singal, "The Price Response to S\&P 500 Index Additions and Delitions: Evidence of Asymmetry and New Explanation," Journal of Finance, 2004, 59 (4), 1901-1929.

Choi, Nicole and Richard Sias, "Institutional Industry Herding," Journal of Financial Economics, 2009, 94 (3), 469-491.

Dasgupta, Amil and Andrea Prat, "Information Aggregation in Financial Markets with Career Concerns," Journal of Economic Theory, 2008, 143 (1), 83-103.

_ , , and Michela Verardo, "Institutional Trade Persistence and Long-Term Equity Returns," Journal of Finance, 2011, 66 (2), 635-653.

_ , _, and _ , "The Price Impact of Institutional Herding," Review of Financial Studies, 2011, $24(3), 892-925$.

Denis, Diane, John McConnell, Alexei Ovtchinnikov, and Yun Yu, "S\&P 500 Index Additions and Earnings Expectations," Journal of Finance, 2003, 58 (5), 1821-1840.

Froot, Kenneth, David Scharfstein, and Jeremy Stein, "Herd on the Street: Informational Inefficiencies in a Market with Short-Term Speculation," The Journal of Finance, 1992, 47 (4), 1461-1484.

Greenwood, Robin, "Short and Long-Term Demand Curves for Stocks: Theory and Evidence on the Dynamics of Arbitrage," Journal of Financial Economics, 2005, 75 (3), 607-649.

Grinblatt, Mark and Matti Keloharju, "The Investment Behavior and Performance of Various Investor Types: A Study of Finland's Unique Data set," Journal of Financial Economics, 2000, $55(1), 43-67$.

_, Sheridan Titman, and Russ Wermers, "Momentum Investment Strategies, Portfolio Performance, and Herding: A Study of Mutual Fund Behavior," American Economic Review, 1995, 85 (5), 1088-1105.

Guerrieri, Veronica and Pter Kondor, "Fund Managers, Career Concern and Asset Price Volatility," American Economic Review, 2012, 102 (5), 1986-2017.

Gutierrez, Roberto and Eric Kelley, "Institutional Herding and Future Stock Returns," University of Oregon and University of Arizona Working Paper, 2009.

Harris, Lawrence and Eitan Gurel, "Price and Volume Effects Associated With Changes in the S\&P 500 List: New Evidence for the Existence of Price Pressures," Journal of Finance, 1986, 41 (4), 815-829. 
Hau, Harald, "Global Versus Local Asset Pricing: A New Test of Market Integration," The Review of Financial Studies, 2011, 24 (12), 3891-3940.

He, Zhiguo and Arvind Krishnamurthy, "Intermediary Asset Pricing," American Economic Review, forthcoming, 2013, 103 (2), 732-770.

Hirshleifer, David, Avanidhar Subrahmanyam, and Sheridan Titman, "Security Analysis and Trading Patterns When Some Investors Receive Information Before Others," Journal of Finance, 1994, 49 (5), 1665-1698.

Kaul, Aditya, Vikas Mehrotra, and Randall Morck, "Demand Curves for Stocks Do Slope Down: New Evidence from an Index Weights Adjustment," Journal of Finance, 2000, 55 (2), 893-912.

Kritzer, Barbara E., Stephen J. Kay, and Tapen Sinha, "Next generation of Individual Account Pension Reforms in Latin America," Social Security Bulletin, 2011, 71 (1).

Lakonishok, Josef, Andrei Shleifer, Richard Thaler, and Robert Vishny, "Window Dressing by Pension Fund Managers," American Economic Review, 1991, 81 (2), 227-231.

_ , , , and _, "The Impact of Institutional Trading on Stock Prices," Journal of Financial Economics, 1992, 32 (1), 23-43.

Malliaris, Steven and Hongjun Yan, "Reputation Concerns and Slow-Moving Capital," Working Paper, Yale School of Management, 2011.

Pedraza, Alvaro, "Strategic Interactions and Portfolio Choice in Money Management: Theory and Evidence," Journal of Money, Credit, and Banking Forthcoming, 2015.

Petersen, Mitchell, "Estimating Standard Errors in Finance Panel Datasets: Comparing Aproaches," Review of Financial Studies, 2009, 22 (1), 435-480.

Raddatz, Claudio and Sergio L. Schmukler, "Deconstructing Herding: Evidence from Pension Fund Investment Behavior," forhtcoming, Journal of Financial Services Reasearch, 2012.

Roll, Richard, "R2," Journal of Finance, 1988, 43 (3), 541-566.

Shin, Hyun Song, "The Second Phase of Global Liquidity and Its Impact on Emerging Economies," Princeton University Manuscript, 2013.

Shleifer, Andrei, "Inefficient Markets: A Introduction to Behavioral Finance," Oxford: Oxford University Press, 2000.

Sias, Richard W., "Institutional Herding," Review of Financial Studies, 2004, 17 (1), 165-206.

Trueman, Brett, "Analyst Forecasts and Herding Behavior," The Review of Financial Studies, 1994, 7 (1), pp. 97-124.

Turner, John A. and David M. Rajnes, "Rate of Return Guarantees for Mandatory Defined Contribution Plans," International Social Security Review, 2001, 54 (4), 49-66.

Vayanos, Dimitri and Paul Woolley, "An Institutional Theory of Momentum and Reversal," Review of Financial Studies, 2013, 26 (5), 1087-1145. 
Wermers, Russ, "Mutual Fund Herding and the Impact on Stock Prices," Journal of Finance, 1999, 54 (2), 581-622.

Wylie, Sam, "Fund Manager Herding: A Test of the Accuracy of Empirical Results Using UK Data," Journal of Business, 2005, 78 (1), 381-403. 


\section{A Appendix A: Tables}

Table 1

Summary Statistics for Colombian Stocks

Key statistics are provided below (at two-year intervals) for the Colombian pension funds. For each column, statistics are shown for the portfolios reported by June 30 of each year, except as noted. The database, made available by the Association of Pension Fund Administrators (ASOFONDOS), includes monthly portfolio holdings of each security in every pension fund from January 31, 2004 to December 31, 2010. Panel A documents the total number of funds, the total assets under management and the share invested in stocks traded publicly in the domestic stock market. Panel B shows the average number of stocks held per fund at each date and the number of different stocks held by all six pension funds as a group. Panel B also provides trading data, inferred from the difference in portfolio holding between May 31 and June 30 of each year.

\begin{tabular}{|c|c|c|c|c|}
\hline & \multicolumn{4}{|c|}{ Year } \\
\hline & 2004 & 2006 & 2008 & 2010 \\
\hline \multicolumn{5}{|c|}{ Panel A. Pension Fund Count, Assets and Asset Allocation } \\
\hline Number of funds & 6 & 6 & 6 & 6 \\
\hline Total assets (\$billions) & 8.2 & 13.8 & 27.8 & 44.1 \\
\hline Net flows (contributions minus withdraws \$billions) & 0.8 & 1.5 & 2.4 & 1.7 \\
\hline Percent invested in domestic stocks & 5.0 & 12.6 & 22.4 & 32.1 \\
\hline Largest fund share (percentage over the pension industry) & 27.1 & 26.6 & 27.2 & 27.2 \\
\hline Smallest fund share (percentage over the pension industry) & 2.9 & 3.8 & 4.5 & 4.8 \\
\hline \multicolumn{5}{|c|}{ Panel B. Pension Funds Domestic Stock Count and Trading Statistics } \\
\hline Average number of stocks held per fund & 16.2 & 21.2 & 26.3 & 30.0 \\
\hline Number of distinct stocks held by all pension funds & 41 & 50 & 44 & 47 \\
\hline Average stocks traded per fund & 7.2 & 5.2 & 8.3 & 7.0 \\
\hline Proportion of trades that are buy (percent) & 65.1 & 61.3 & 80.0 & 54.8 \\
\hline Total buys (\$millions) & 14.1 & 20.3 & 82.7 & 50.7 \\
\hline Total sells (\$millions) & 4.5 & 16.3 & 23.9 & 80.0 \\
\hline Average yearly sells (percentage of sell volume over total trades) & 27.4 & 25.4 & 29.2 & 65.4 \\
\hline
\end{tabular}


Table 2

Summary for stocks

This table presents monthly averages of stock-level information, classified by marketability $H I G H$ and $L O W$ as reported by the SFC, and split by period, before the MRG change and after.

\begin{tabular}{|c|c|c|c|}
\hline & \multicolumn{3}{|c|}{ Monthly average across stocks } \\
\hline & All stocks & High Marketability & Low Marketability \\
\hline \multicolumn{4}{|l|}{ Abnormal Returns } \\
\hline Before June 2007 & $0.1 \%$ & $0.06 \%$ & $0.13 \%$ \\
\hline After June 2007 & $-0.1 \%$ & $-0.06 \%$ & $-0.13 \%$ \\
\hline \multicolumn{4}{|l|}{ Volume (\$millions) } \\
\hline Before June 2007 & 9.97 & 18.71 & 2.15 \\
\hline After June 2007 & 16.51 & 30.59 & 1.58 \\
\hline \multicolumn{4}{|c|}{ PFA Demands/Stock Average Trading Volume } \\
\hline Before June 2007 & $18.19 \%$ & $16.09 \%$ & $25.66 \%$ \\
\hline After June 2007 & $26.63 \%$ & $27.46 \%$ & $21.36 \%$ \\
\hline \multicolumn{4}{|c|}{ Correlation 1-month returns } \\
\hline Before June 2007 & $29.31 \%$ & $41.8 \%$ & $9.8 \%$ \\
\hline After June 2007 & $29.39 \%$ & $46.3 \%$ & $9.67 \%$ \\
\hline \multicolumn{4}{|c|}{ Correlation 6 -month returns } \\
\hline Before June 2007 & $32.75 \%$ & $44.47 \%$ & $15.81 \%$ \\
\hline After June 2007 & $31.8 \%$ & $49.66 \%$ & $10.5 \%$ \\
\hline \multicolumn{4}{|c|}{ Price non-synchronicity 6 months } \\
\hline Before June 2007 & 1.99 & 1.06 & 3.31 \\
\hline After June 2007 & 2.8 & 0.95 & 5.01 \\
\hline
\end{tabular}




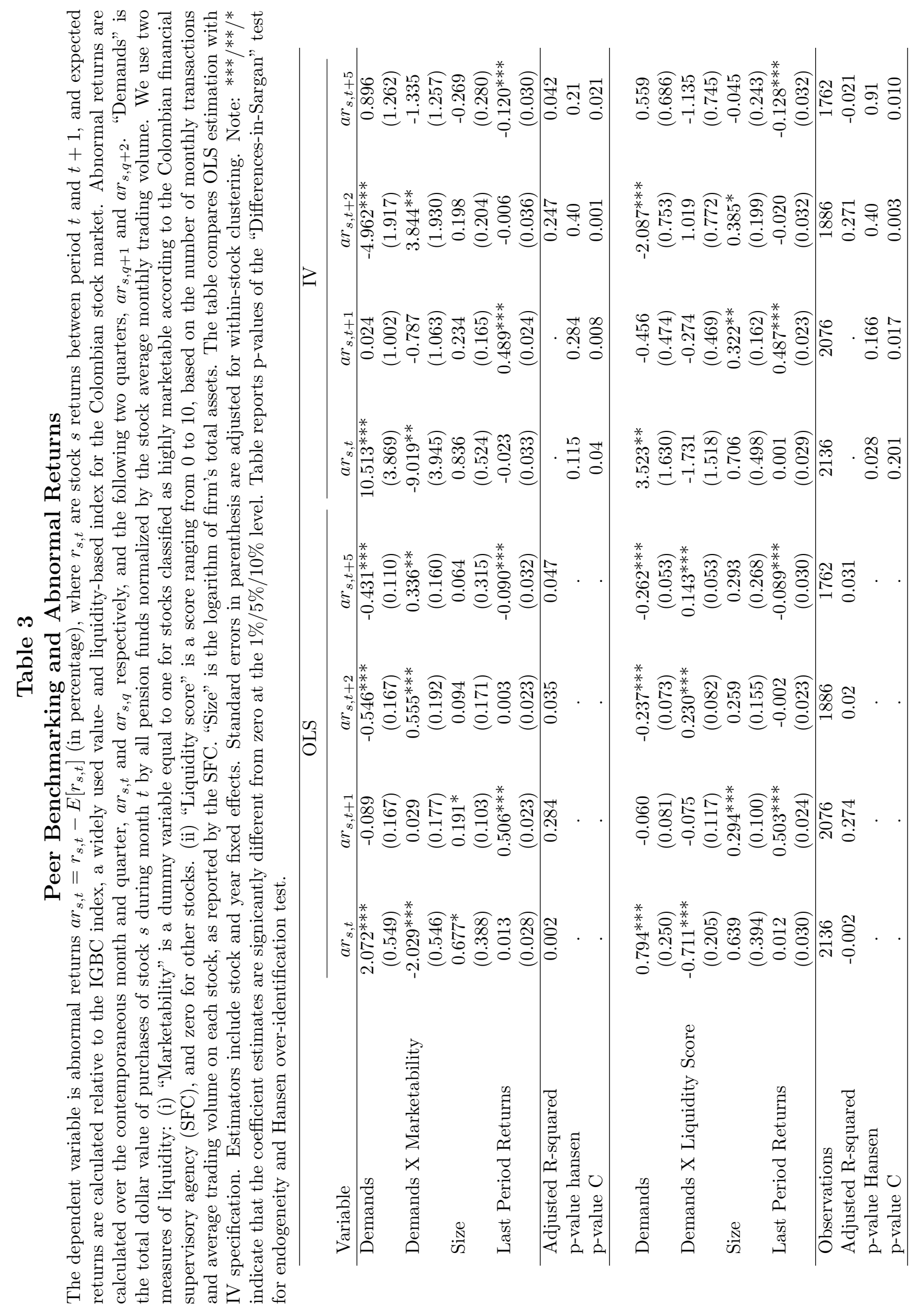




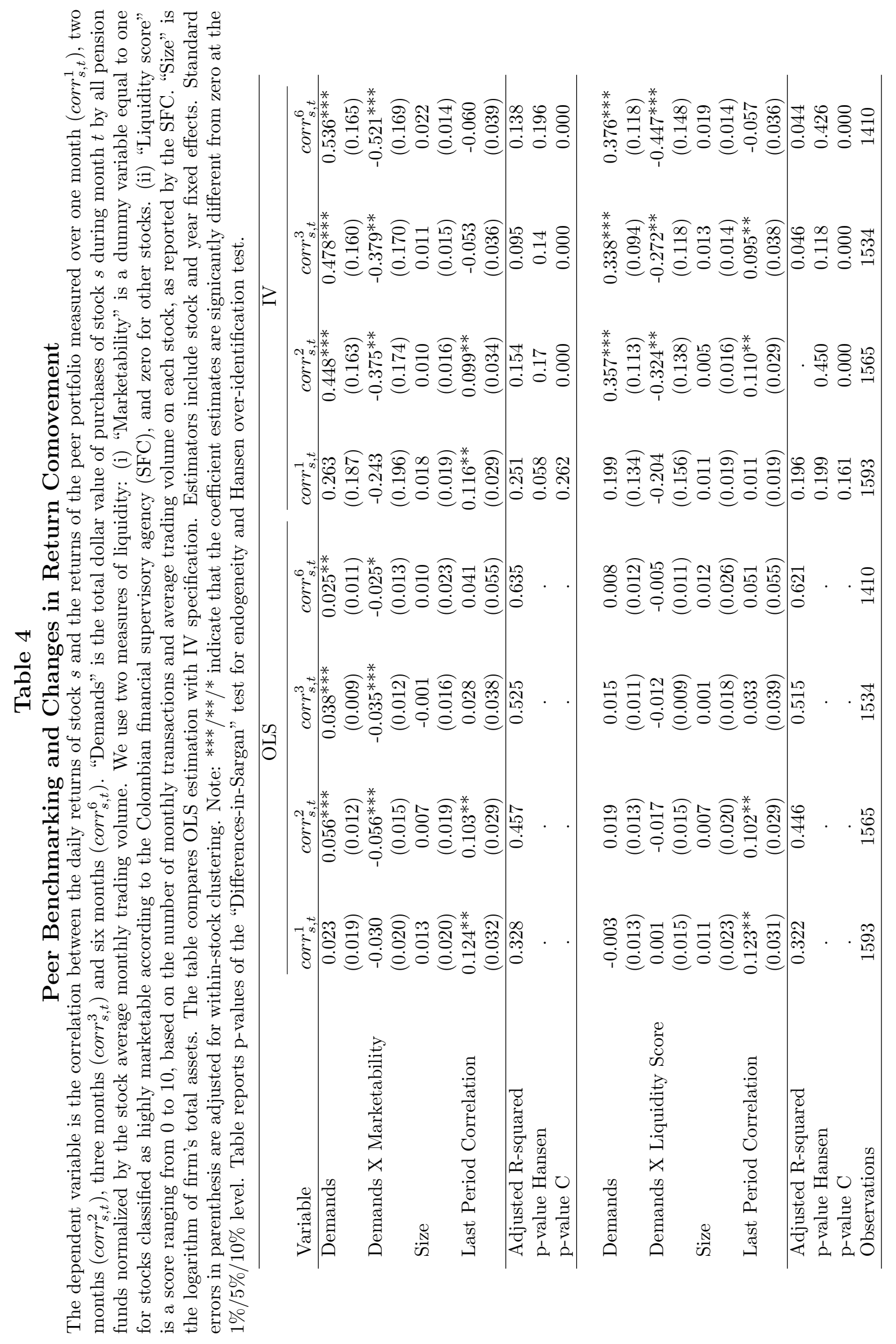




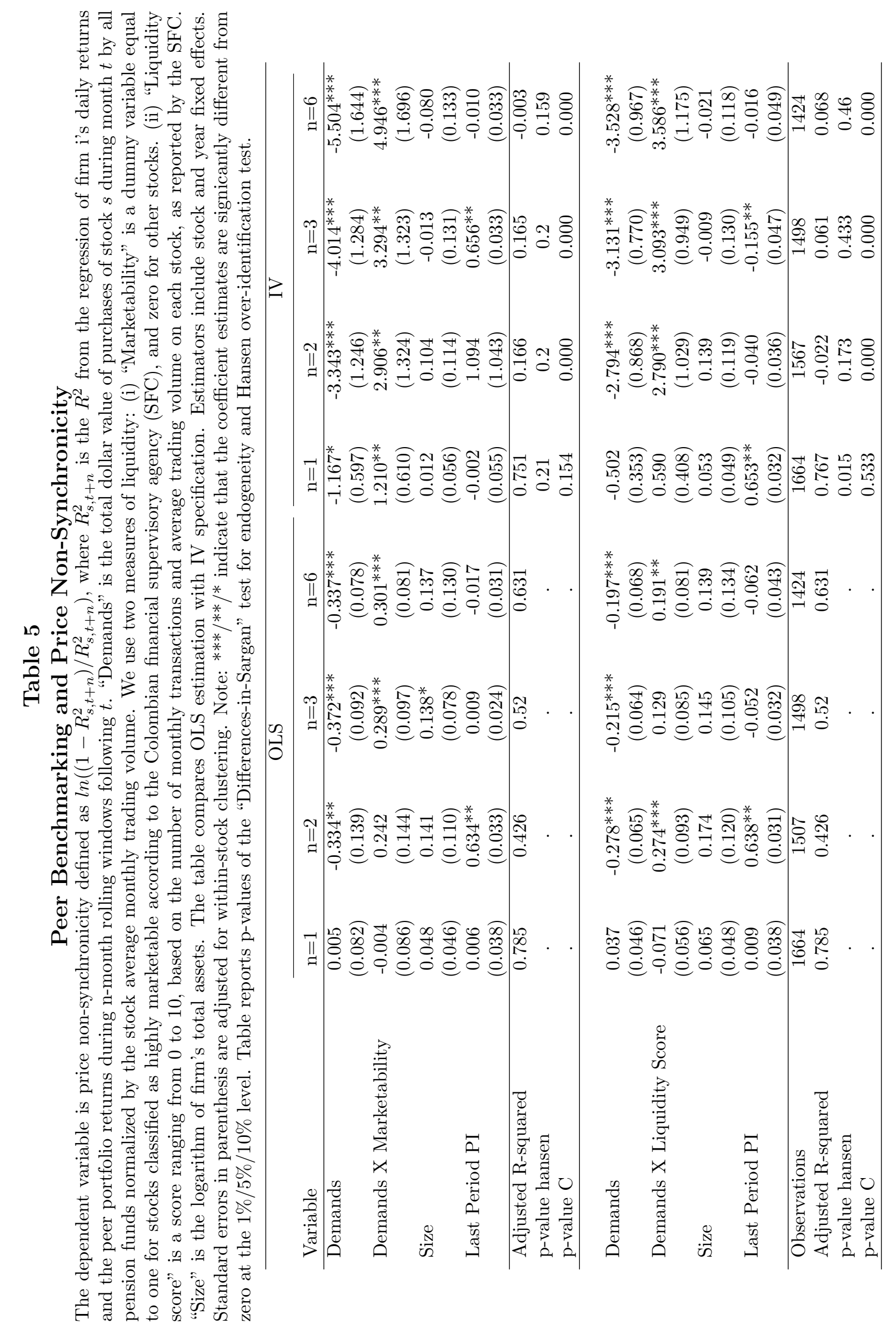




\section{B Appendix B: Figures}

Figure 1. Trades before and after the MRG change. Correlation between pension fund demands and (i) lagged overexposure, $\operatorname{corr}\left(y_{i, s, t}, \exp _{i, s, t-1}\right)$ (solid line) and (ii) the interaction between lagged overexposure and relative returns, $\operatorname{corr}\left(y_{i, s, t}, \operatorname{oexp}_{i, s, t-1} \times \operatorname{rel}_{i, t-1}\right)$ (dotted line).

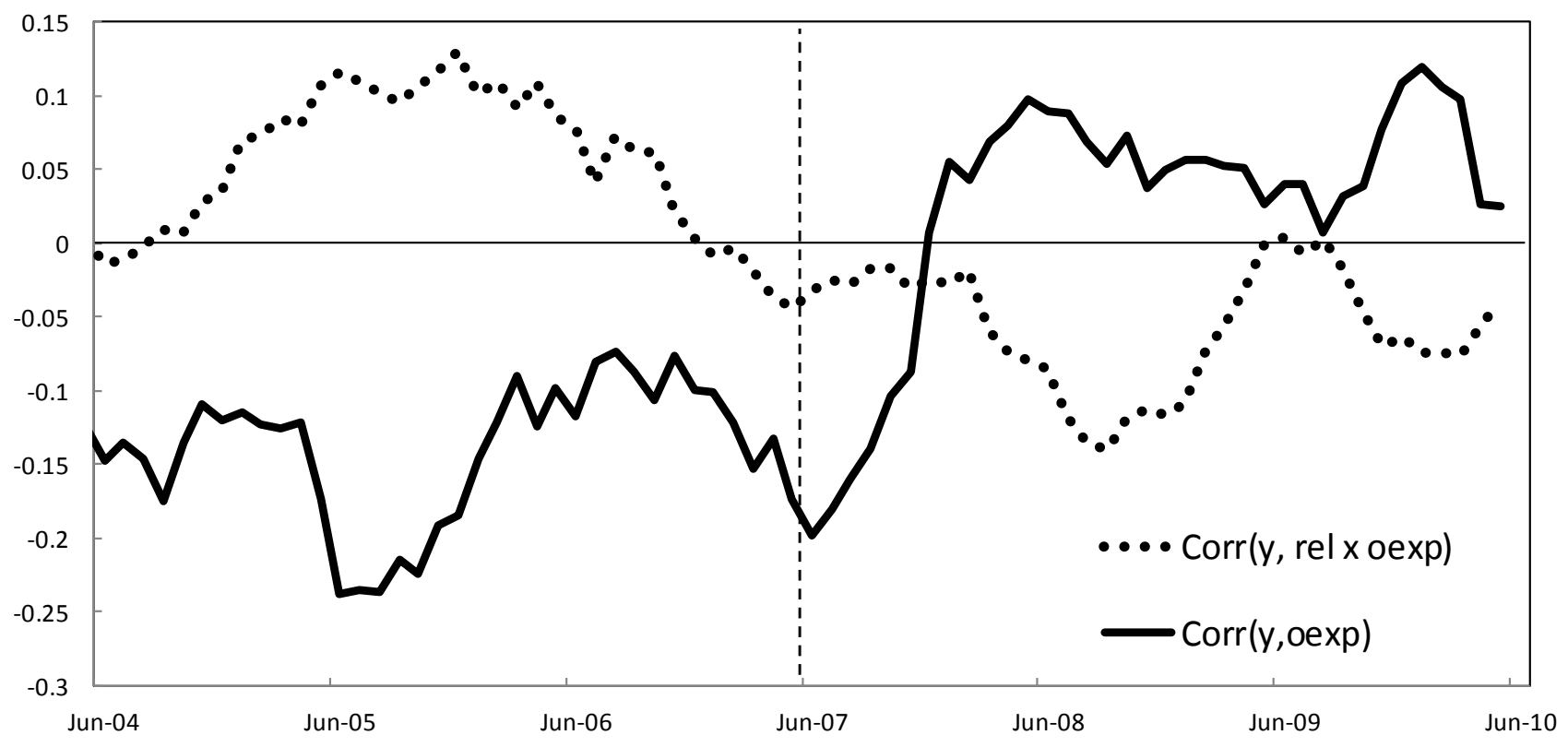


Figure 2. Marginal effects on abnormal returns. Estimated marginal effects of pension fund demands on stocks' abnormal returns $\frac{\partial a r_{s, t}}{\partial y_{s, t}}$ with $95 \%$ confidence bands. Each panel compares results from OLS and IV specifications for abnormal returns measured during the contemporaneous month $\left(a r_{s, t}\right)$, contemporaneous quarter $\left(a r_{s, q}\right)$, and during the next two quarters $\left(a r_{s, q+1}\right.$ and $\left.a r_{s, q+2}\right)$ following the trades of pension funds.

(a) $a r_{s, t}$
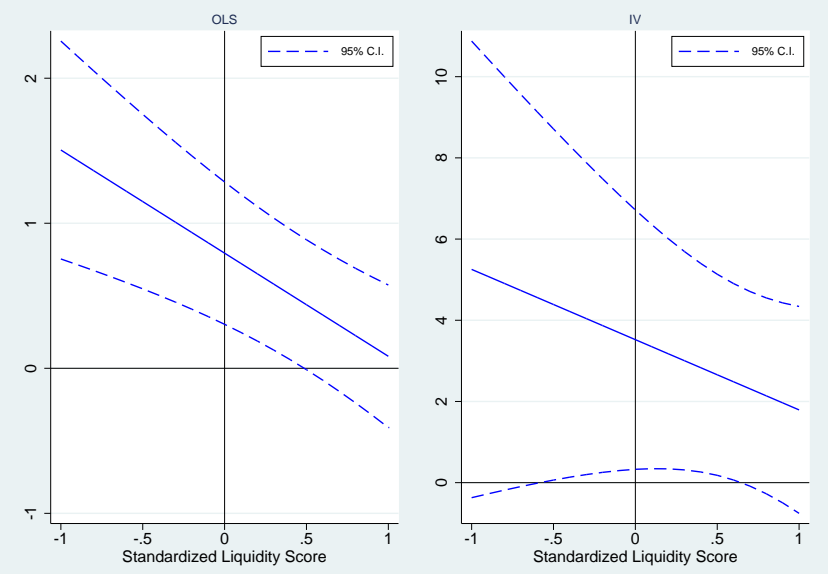

(c) $a r_{s, q+1}$
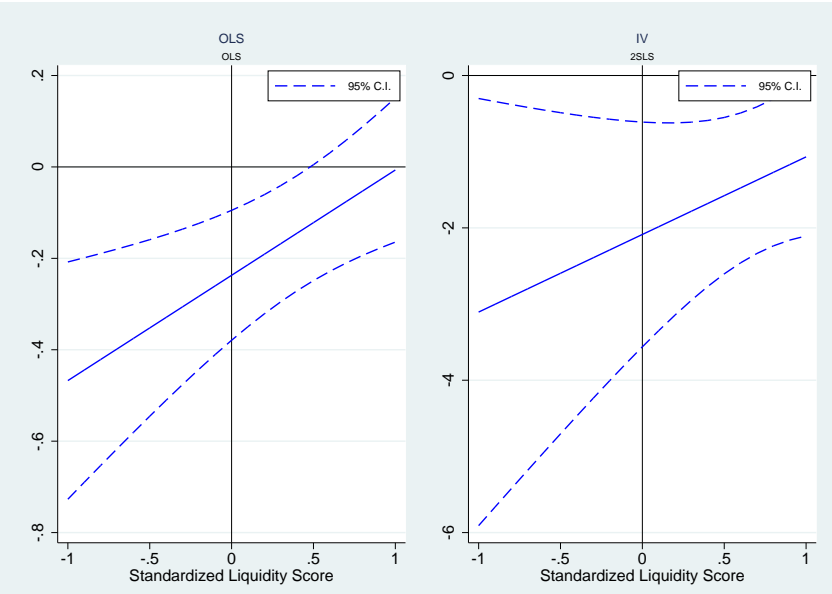

(b) $a r_{s, q}$
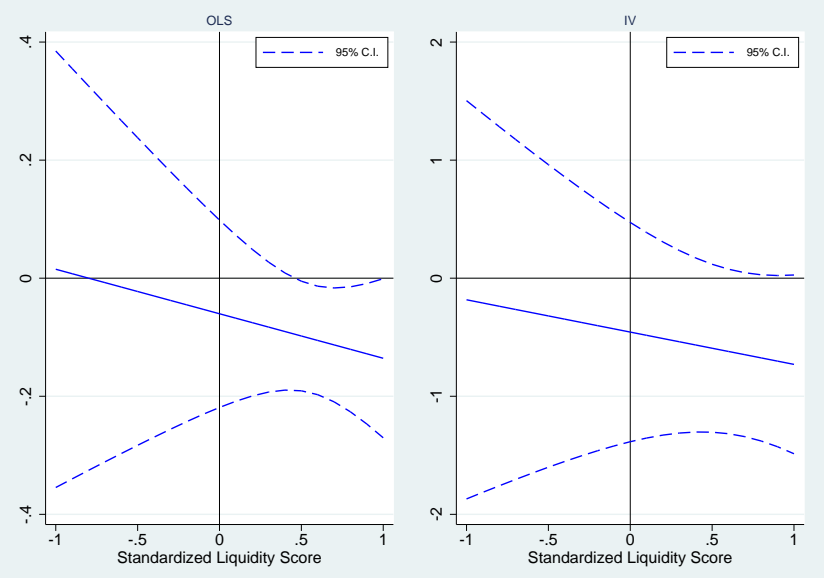

(d) $a r_{s, q+2}$
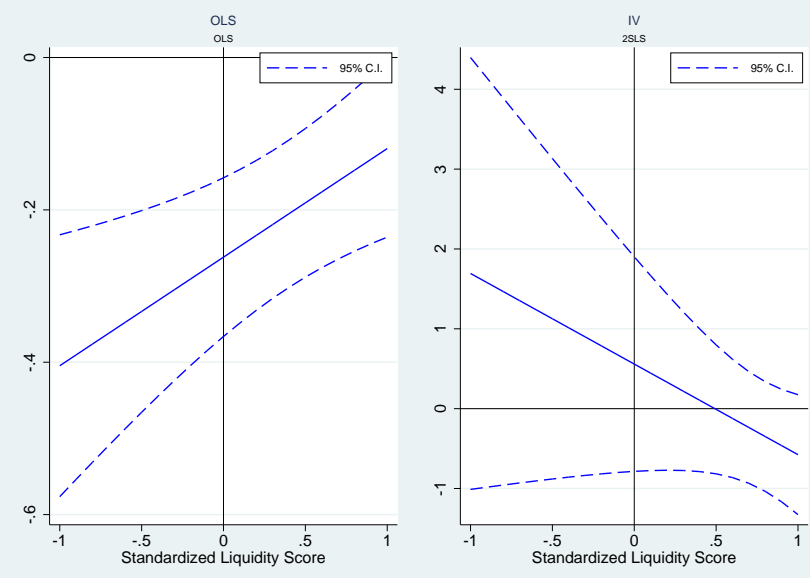
Figure 3. Marginal effects on comovement. Estimated marginal effects of pension fund demands on the correlation between daily stock returns and peer portfolio returns $\frac{\partial \operatorname{corr} s_{s, t}^{n}}{\partial y_{s, t}}$ with $95 \%$ confidence bands. Each panel compares results from OLS and IV specifications for return correlations measured over one month, two months, three months and six months rolling windows following the trades of pension funds.

(a) One month

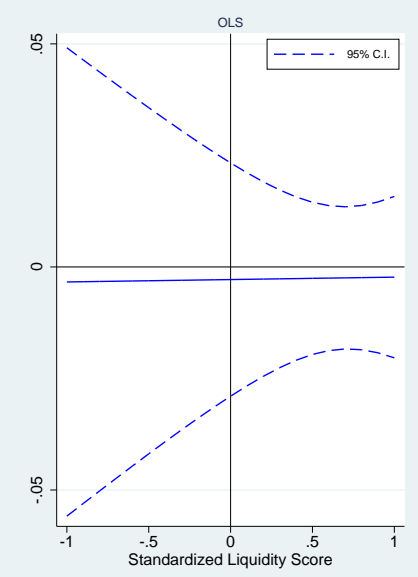

(c) Three months

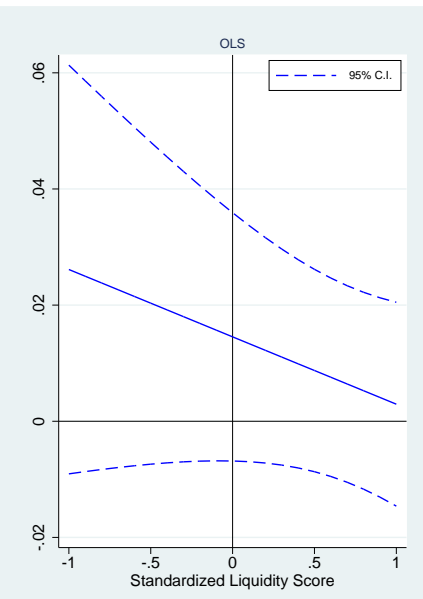

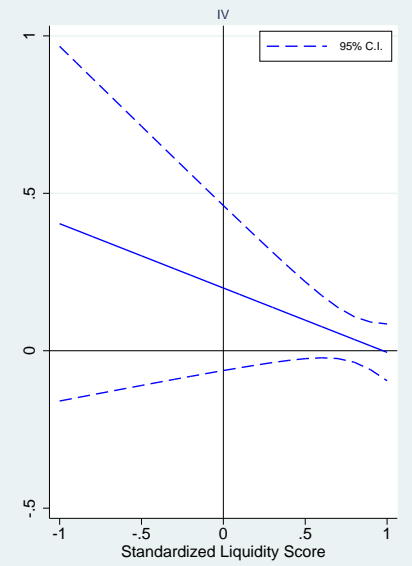

andardized Liquidity Score

(b) Two months
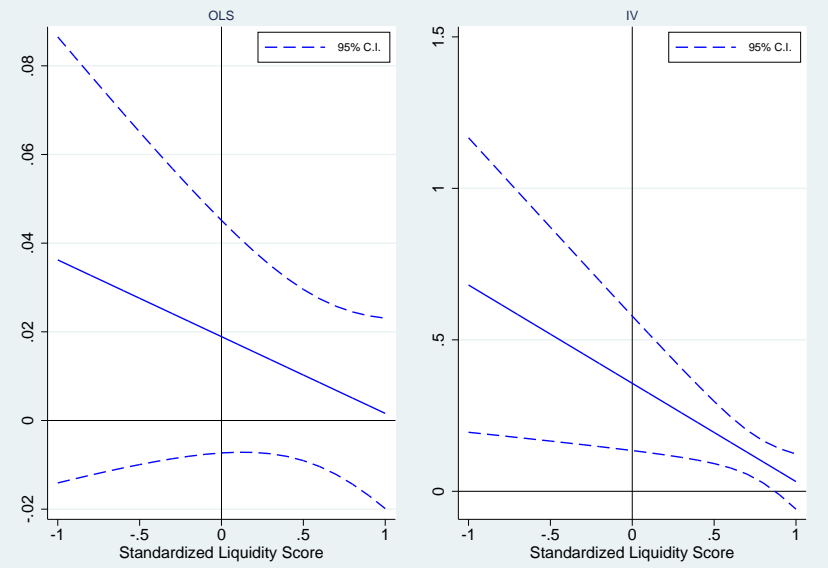

(d) Six months
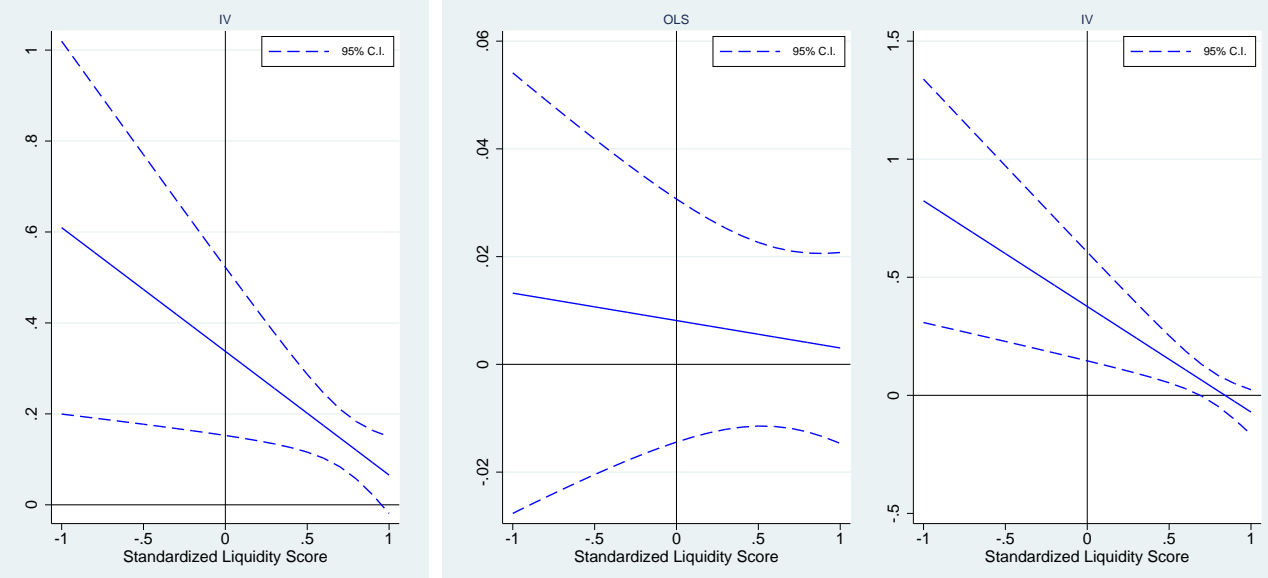